receive special attention, and are picked out of the inmense mass of chemical details that render ordinary text-books on organic chemistry so hopeless to any one who has not had a thorough chemical training.

The translator has done his part of the work well, and has added material where he considers such necessary for the somewhat different requirements of English students. The additions in the text are enclosed in square brackets, so that one can readily distinguish them from the author's work. A few changes in arrangement have also been made. The book contains 242 pages, and an appendix on methods by the translator. The first lecture is devoted to a historical survey of the rise of organic chemistry during the last decades. Hydrocarbons are then considered: methane, ethane, and their derivatives come next. Glycerol and the fats, carbohydrates, glucosides, cyanogen compounds, urea and its derivatives, aromatic compounds, alkaloids and proteins, are among the subjects discussed in detail.

The work is much in excess of the requirements of medical students, but is strongly recommended to any one who wishes to obtain a thorough grasp of the subject. The translation is good, and the subject-matter contains, in addition to the necessary technical details, much that is of general interest.

\title{
NOTES ON BOOKS.
}

In The Care of the Body, the latest of Messrs. Methuen \& Co.'s "New Library of Medicine Series," which is intended to place the views of modern scientific medicine before the public, Dr. Cavanagh deals in a most breezy and stimulating manner with the generalities of personal bodily hygiene and the commonplaces of everyday life. The subjectmatter is treated in a manner which at times seems almost casual, but yet is throughout strictly reasoned and orderly; probably it is the best method of impressing on an age already over-burdened with undigested information, facts which, although many are well known, are neither properly appreciated nor acted upon. The different chapters deal with sleep, baths, exercise and training, fatigue, clothing, the skin, the hair, the teeth, feet and hands, light and ozone, the eyes, ears, nose, position and habit. Dr. Cavanagh is no great believer in artificial systems of training; he prefers walking or running to any of them as an exercise and developer of the body. The chapter on clothing is particularly harrowing; the function of clothes is to keep the body temperature at $98^{\circ} .4 \mathrm{~F}$., and, from this standpoint, fashions come in for much trenchant criticism. The last chapter is on "The Function of the Physician," and is the keynote of the whole problem - that it ought to be preventative, and not curative; and the sooner our social organisation adopts this view the better it will be for the race.

Dr. Robert Jones has published for the use of asylum nurses (and their teachers?) an excellent text-book on Mental and Sick Nursing (Scientific Press, London).

This work we can most heartily recommend. It gives the necessary physiological and psychological groundwork for a proper conception of 
insanity, without which the nurse's work can neither be so interesting for herself nor so satisfactory for the patient. Instruction is given, not merely in mental nursing, but also in the management of bodily disease, which should be of especial value for those nurses who have not had a previous hospital training. Without this knowledge a nurse can never hope to properly undertake the management of private cases. Nurses are perhaps born, not made, but, so far as any book can make them, this one will.

A Manual for Hospital Nurses, by E. J. Domville (J. \& A. Churchill, London), would form a good introductory book for a nurse to read; the style is clear and interesting, although inevitably rather condensed. It contains, firstly, a chapter on "A Nurse's Duties and Responsibilities," then a section on "The Nursing of Ordinary Cases," and one on "Emergency Cases, Operations, and Special Cases." Lastly, there is an appendix dealing with "Preparation of Remedies, Cookery, Measures, etc.," and a "Glossary of Terms."

Of Dr. Cullingworth's Short Manual for Monthly Nurses (J. \& A. Churchill, London) little more need be said than that it is excellentfor the monthly nurse- but noting that it is not intended for the use of midwives.

The "Practical Medicine Series" (Year-Book Publishers, Chicago) has been already referred to in these Notes. Vol. vi. has now reached us. It is entitled General Medicine, but nearly half of the volume deals with typhoid and tropical diseases, the remainder being entirely devoted to the alimentary system.

While this series is published primarily for the general practitioner, at the same time the arrangement in several volumes enables those interested in special subjects to buy only the parts they desire. An attempt has been made in this volume of 343 pages-The Eye, Ear, Nose, and Throat, edited by Casey A. Wood, C.M., M.D., D.C.L. (Gillies \& Co., Glasgow)-to review the literature on the subjects under discussion for the year previous to publication. This results in a book which is intended to furnish the practitioner with a ready reference to the most recent methods of examination and of treatment. For the specialist it is not of sufficiently wide scope to enable him to neglect his own reading. Considering these facts, we think notices of papers devoted to a description of rare cases, or to anatomical studies of purely academic interest, might have been omitted. On the whole, however, the editors may be congratulated on the results of their labour. A fuller index would make reference easier.

The object of this book-Diseases of the Nose and Throat, by B. J. Johnston, M.D. (Hodder \& Stoughton, London)-is " to present in concise and practical form the diagnosis and treatment of the various diseases ordinarily found in the nose and throat." We are afraid that the most lenient critic could not be satisfied that this object had been attained. An undue amount of space has been devoted to illustrations of instruments and to prescriptions. The instructions as to methods of examination are faulty. The descriptions of the various diseases are not clear, and in some cases 
inaccurate, while the space is not well apportioned. Thus a chapter of three pages is devoted to so-called "Diseases of the Uvula," while "Paralysis of the Vocal Cords" is discussed in two pages and a line ; and here we find the following remarkable statement: "Abductor paralysis is rather rare, is serious, and is usually a sequel of erysipelas, pneumonia, or typhoid fever." Further comment is needless.

Dr. Seymour Taylor has published his post-graduate lectures at the West London Hospital, On Acute Pneumonia (H.J. Glaisher, London), in pamphlet form. They give in comparatively few pages a good clinical study of this perennially interesting malady, and set forth in a suggestive way the indications which modern research affords as regards treatment of a disease which is probably more frequent, and certainly more fatal, than a generation back.

In many respects, The Eddy (W. Blackwood \& Sons, Edinburgh) marks a distinct advance on Mr. Riccardo Stephens' earlier novels, although it is by no means free from the blemishes which marred these. It is a study of the career-the downward career-of a well-bred, well-educated doctor, driven partly by circumstance, partly by temperament, to practise as a parish medical officer in the Scottish Highlands. Ground between the upper and the nether millstones of a peculiarly snobbish set of shooting tenants and a peasantry thrifty even to avarice, Dr. Amory falls a victim to drink, and ends his days in pitiful fashion. The plot is slight, and Mr. Stephens has not the knack of enlisting our sympathy for his puppets: Battye, the well-intentioned, is a bit of a prig, the crofters are too greedy to live, and the Highland Provost's speech is an extraordinary jargon of lowland Scots. Amory's wife is well drawn, and the descriptions of sport are admirable. The Eddy is a much more serious work than any of Mr. Stephens' earlier romances, and though not a complete success comes within measurable distance of it.

Many a young medical practitioner fresh from the wards of the hospital is doubtless ill versed in the minor ailments of his patients, and it is with the object of meeting this deficiency that Dr. W. Essex Wynter has written Minor Medicine: a Treatise on the Nature and Treatment of Common Ailments (Sidney Appleton, London). "A chill on the liver," relaxed throat, sea-sickness, sprains, neuralgia, baldness, and other kindred affections are among the subjects dealt with. The book, which is written in a pleasing conversational style, gives a comprehensive account of the treatment of the minor ailments; there is not much said regarding diagnosis. We are not a little astonished at the length of some of the author's prescriptions, certain of which contain ten, or even eleven, ingredients.

It is manifestly impossible to do justice to the whole subject of general pathology and morbid anatomy in a manual of 285 pages; but in this small work-Pathology, General and Special, by John Stenhouse, M.B., and John Ferguson, M.D. (Hodder \& Stoughton, London)-a praiseworthy attempt is made to give as much information as can be condensed into so small a compass. The text has been carefully written, and, as evidence that the reader will find no unnecessary padding, we note that the subject of anthrax is treated of in ten lines, and diseases of the pancreas in nine. 
This book-The Skin Affections of Childhood, by H. G. Adamson, M.D., M.R.C.P.- fills a gap in pediatric literature, and supplies a longfelt want, which will be heartily welcomed by those interested in the subject. The little volume lays no claim to be an exhaustive treatise, but is simply a short practical epitome, written in a clear and concise manner, which should prove useful alike to the practitioner and the student. In a future edition the value of the work would be enhanced by greater space being devoted to the question of treatment and by a considerable addition to the number of illustrations.

The eighteenth volume of the Transactions of the American Pediatric Society, recently published, contains thirty papers read before the Society. Many of these papers are of more than average merit, but the one which calls for special notice is a paper on "Pseudoleukæmia Infantum" (von Jaksch) by Koplik. The author considers that it is a secondary anæmia with or without leucocytosis, and that those cases reported as terminating in leukæmia were really cases of leukæmia from the outset.

As usual, the volume is excellently printed and well illustrated, and reflects credit alike on the editor and publisher.

Professor von Schrötter's old students, of whom there are many in this country, will find much to interest them in this little volumeHygiene of the Lung in Health and Disease (Rebman Ltd., London) Written as one of a Health Series in Austria, the book covers the various aspects of lung hygiene in pleasant fashion. The original, with its chatty tone, is perhaps more characteristic of the author than is the translation. The latter, however, is sufficiently well done.

The structural and functional activity of the lungs is considered, and then the care of the healthy lung under extremely varying conditions of environment. The last chapter is devoted to diseases of the lungs, including the effects of inhalation of poisonous gases. The book, which was primarily addressed to a popular audience, contains shrewd hints which may be found of service even to the trained practitioner. The extent to which open-air measures may be practised is stated more guardedly than is accepted by most authorities in this country, but allowance has to be made for the difference in national outlook and custom. Altogether the book is one which ought to be of considerable service in helping people to keep their lungs in health and so exclude disease.

This-Diseases of the Male Generative Organs, by Edred M. Corner, F.R.C.S.-is one of the Oxford medical Manuals, and is an attempt to present a practical survey of the diseases of the generative tract, uncomplicated by a consideration of those of the urinary tract. There are numerous illustrations, which are more or less diagrammatic, but which have the merit of being simple and easily interpreted. The writing is clear in style, but seems too sketchy and incomplete to be of much value to either practitioners or students, and we have a difficulty in determining for what class of reader this work is intended. 